\title{
Human Capital and the Middle Class in the XXI Century: Characteristics and Role in Achieving Economic Steadiness, Social Security and Political Stability
}

\author{
Dmytro Melnychuk* [0000-0002-9918-0608], Liudmyla Mohelnytska [0000-0002-1570-1200]
}

\author{
Zhytomyr Polytechnic State University, Zhytomyr, Ukraine \\ *melndp@ukr.net
}

\begin{abstract}
The article is devoted to the crucial problems of the middle class formation and to the clarification of its role in the XXI century. In the course of the research the authors analyzed the functions of the middle class and the regularities of its formation. The article considers the importance of progressive changes in the society social structure based on the creation of conditions for the application of knowledge, skills and competences of the working population in the form of profitable economic assets, i.e. human capital. The main goal of the study is to prove the crucial role of the formation of a powerful middle class, and hence the progressive transformation of the society social structure, which is a prerequisite for economic steadiness, political stability and social security. The negative course of the relevant processes in developing countries has determined the relevance of the chosen topic. The generalization of theoretical sources and the analysis of the existing methodological tools made it possible to distinguish two main approaches to the fact of the middle class existence with its inherent stabilizing functions: monetary and sociological. This helped to define the main hypothesis of the study: only the presence of positive conclusions, both in terms of monetary and sociological approach, will allow us to report about the formation of the middle class as a driving force of socio-economic development. The novelty of the study is obtaining and interpretation of fundamentally new data on differences in the assessments of the middle class segment on monetary and sociological approaches in Ukraine, as a country seeking integration into the community of the European Union. This contributed to the formation of recommendations aimed at establishment of the middle class powerful core in Ukraine and other countries that are developing and seeking to achieve standards of economic steadiness, political stability and social security.
\end{abstract}

Keywords: human capital, middle class, population structure, quality of life, economic steadiness, social security, political stability.

\section{INTRODUCTION}

In recent centuries, humanity has taken a decisive step from primitive to progressive knowledge, moving from the priority of professional skills, formed through self-learning and long repetition of similar production functions, to the priority of professional competence, which is the result of long training and significant investment in education. High demands of scienceintensive industries have led to the perception of human knowledge, practical skills and professional competence from the standpoint of priority investment object. They caused a high concentration of money in education and science, necessitated a change in the prevailing paradigm of social development. This marked the emergence and testified to the dominance of a fundamentally new form of capital - human capital.

Human capital is rightly understood as an economic asset that is formed as a result of social investment in education, health care and training. Human capital is created by acquiring knowledge, skills, professional competence and is a form of their representation in the labor process, which provides a certain income to all participants in the investment and production process. However, human capital is not only a specific form of expression of productive abilities of a man or society as a whole, which under certain conditions is realized in 
the social and labor sphere. At the same time, it is a factor that causes changes in the patterns of distribution and redistribution of newly created value in the system of socio-economic relations and thus has a significant impact on the transformation of the social structure of society, which as a result acquires new, progressive features. Its dominant component is the middle class. In the XXI century such structural changes accelerate the development of the post-industrial economy, ensure the stability of economic systems, increase social security guarantees, protect against political instability and its negative consequences.

Conversely, the lack of positive trends in the middle class leads to radically opposite changes: lower living standards and quality of life for all segments of the population, destabilization of the political situation, the impossibility of practical implementation of social security principles. The complexity and acuteness of the socio-economic problems prove the importance and relevance of studying the regularities observed in the creation of conditions for the application of knowledge in the form of capital. Capital is an economic asset, which is a powerful factor in the middle class segment and hence the determinant of rationalization of its influence on the steadiness, social security and political stability in the country.

\section{RESEARCH METHODOLOGY}

The middle class is the stratum of the population that represents innovative judgments and values of modern economic and political culture. It is the key to social development of the state. In view of this, the methodological basis of the study was the theoretical generalization of progressive scientific judgments, the use of statistical analysis and sociological surveys. This made it possible to analyze the dynamic processes occurring in the society structure, to determine their causes and consequences. The applied research methods provided versatility and reliability of the received information, made it possible to clarify the current ideas in science about trends in the middle class segment.

The process of sociological research on the problems of the middle class formation included theoretical, methodological and organizational stages, during which the hypothesis and scientific problem, goals, tasks, object and subject of research were formulated. Sampling, methods of data collection, processing and analysis were substantiated. Sociological research plan was developed. This methodological approach provided a comprehensive theoretical basis for the authors' conclusions and assumptions. It enabled the authors to obtain, interpret and correctly compare statistical and sociological data, to make conclusions and recommendations aimed at creating conditions conducive to a strong middle class formation in order to ensure economic steadiness, political stability and social security of the state.

\section{RESEARCH ANALYSIS}

Research results. In a market economy, human capital is the most important factor of power and influence, both nationally and geopolitically. Thus, as a result of a human capital study, T. Schultz came to the following conclusions:

- there are no fundamental differences between human and material capital, both bring income;

- investment in human capital is ahead of investment in industrial capital, so the ownership of industrial capital becomes secondary;

- the growth of investment in people significantly changes the structure of wages: the main part of it is income from human capital;

- society, investing more in a man, can achieve not only the growth of the product, but also a more even distribution of it [1].

In terms of the research, the latter statements deserve special attention, because, as a result of social investment, the functioning of productive human capabilities in the form of capital causes an increase of the middle-income population, which indicates the replacement of the conservative model of social structure to the progressive one.

\section{THE MAIN MATERIAL}

Conservative social structure is characterized, on the one hand, by the existence of a few higher circles, whose representatives have high incomes and enjoy various privileges of power, and on the other hand by the presence of a large share of the population, receiving meager incomes, having low purchasing power, and is removed from a fair distribution of production results. Instead, a peculiarity of the progressive social structure is the prevalence of the middle class, which forms the segment of the population that serves their own lives, based on the priority of private property rights, as well as productive, creative, intellectual work. It is not private ownership of the material means of production, but the individual ownership of the person who is the direct carrier of knowledge and information, that is becoming functionally dominant in the economy of the $21 \mathrm{st}$ century. It is on this basis that the social structure of society is adjusted, in which the leading role is taken over by the class that is the carrier of knowledge. The dominance of this class is the fundamental difference between the modern, post-industrial, information society and the society of classical capitalism.

What is the connection between the concept of human capital, the social structure of society and the 
formation of the middle class? As a result of the theoretical study, the authors found out that human capital, like any form of capital, forces stakeholders to take into account their important role in the process of social production. As the history of social development has shown, the rapid scientific and technological progress of recent decades has proved to be the most effective lever for raising the level and improving the quality of life of workers and their families. Now in the civilized world, due to a series of scientific and technological revolutions and the complexity of production technologies, knowledge and skills have become so important that they have been able to act as an effective tool for radically updating the model of the relationship between capital and wage labor. The fact that the average worker acquires progressive knowledge and professional skills has led to a change in the very principle of the distribution of surplus value between actors on the stage of capitalist production. And if earlier the increase in value was unquestionably appropriated by the owner of the means of production, now the latter is forced to share part of the newly created value with his «partner» - the owner of another kind of capital, who along with industrial capital takes an active part in the production process. This owner is an owner of human capital [2].

In the XXI century, it is the characteristics of human capital that directly determine the negotiating position of the employee, because the latter, as its owner, on the one hand, is entitled to a part of the newly created value. On the other hand, that is much more important, through strengthening individual negotiating position the employee becomes able to influence the nature of the distribution of such value among all participants in capitalist production. This directly applies to modern models of socially oriented market economies, which, one way or another, remain essentially capitalist. And it is the existence of conditions for the detection of the phenomenon of human capital, and thus an increase in the share of the middle class, that currently distinguishes successful countries from those whose economic systems steadiness and political stability are in constant doubt.

In view of this, before using the term "human capital" and thinking about the prospects of economic steadiness, social security and political stability, it is worth considering whether knowledge and work skills really play the role of an economic asset in a given society. Are they able to act as a capital that balances the rights of the employee and the owner of the means of production as subjects of distribution and appropriation of a certain part of the newly created value? It is important that in those countries where knowledge and various productive abilities of a person are so developed that they really function in the form of capital, citizens generally live better. They receive a salary that not only covers the costs associated with the need to reproduce the workforce, but also contains a certain surplus, which enables people to increase wealth and form bank deposits, buy tours and visit exotic countries, to constantly improve their living conditions. Instead, where knowledge is unable to acquire the characteristics of capital for a number of reasons, the vast majority of employees are depressed: «... not only the material but also the spiritual sphere suffers, as there are not enough funds for the things that turn existence into real life: for education, travel, health support, recreation and charity, heating, food and shelter» [3]. And the point here is not in the wrong theory of human capital, that its critics try to prove, but in the fact that today not every state has evolved to the level at which knowledge becomes capital and thus contribute to the progressive transformation of social structure. The vast majority of countries are still captivated by outdated stereotypes of market space organization and a lack of understanding of the true role of competitive knowledge in achieving economic steadiness, social security and political stability.

Human capital should be considered the main economic attribute of the modern state, where the share of the population that can embody the features of the owner of this asset is dynamically increasing. The content and nature of work encourages the acquisition of unique, deep, specific knowledge of extremely high market value. The latter, in its turn, will guarantee a quick return on investment in the educational process. And if industrial society is identified by the number of goods that determine the standard of living, then postindustrial society is characterized by the quality of life, which is reflected in services and various conveniences in health, education, recreation and culture that become available and prove success along the way of achieving a high level of social security. At this stage, the influence of a new type of consciousness becomes noticeable, which is primarily represented by the middle class. The post-industrial era is the result of a long chain of technological change; not all countries, but only a few have joined or are ready to join. D. Bell aptly noted that the information society is a society in which there is scientific potential and the ability to transform scientific knowledge into the final product [4]. The same applies to human capital, because only a small number of countries can be proud of the discovery of this socio-economic phenomenon, and hence its rational impact on the population structure, leading to the progressive transformation of the latter.

Analyzing the problem of progressive transformation of the society social structure and the formation of a powerful middle class, as well as the relationship of these processes with the ideas of human capital theory and the expected positive trends in economic steadiness, social security and political stability, it should be noted that: 
- in a post-industrial society, which is enlarged by an increasing number of countries, the leading position is occupied by the middle class; at the same time, this layer becomes structured, acquires a clear form, develops its own rules and methods of fighting for its interests;

- the middle class is not just the social stratum of the population, which is determined by quantitative characteristics depending on the level of income, it is the carrier of a certain ideology and values;

- the middle class is the basis of social, economic and political stability in the state, the key to its dynamic development, and its active participation in public life determines the success of democratic transformations [5].

It is worth noting that there are two main approaches to singling out he middle class: monetary and sociological. According to the first of them, the middle class, as a stratum, is studied from the standpoint of the income parameter, using the median tools of economic analysis. In this case, the middleincome group is the one located within $75-200 \%$ of the median income of the population. According to the second approach, the middle class is differentiated according to the functions inherent in this stratum of society in a developed society, and compared with the representatives of the middle class traditional professions. According to the authors, it is the monetary approach that has been and should remain the methodological basis for the differentiation of the study group, because only the level of income and the nature of costs can indicate the presence or absence of the middle class. However, from the standpoint of the monetary approach, the analysis of the population income structure in many countries, including Ukraine, does not give grounds for positive conclusions about the existence of the middle class as such.

Thus, with regard to the situation in Ukraine, it can be stated from the standpoint of monetary analysis that Ukrainian society has undergone various promising transformations, but inefficient income distribution policy has hindered the formation of the middle income group, which should become the basis of the middle class. It has not given any chances for progressive changes in the social structure of society. According to 2019 data, $56 \%$ of the Ukrainian population occupies a position between the poor and middle-income groups, and it is mainly this cohort that includes representatives of traditional middle-class professions. The average income group in 2019 was only $13 \%$. It has decreased by $3 \%$ compared to 2000 [6, p. 81], which clearly demonstrates the lack of positive trends in the formation of a significant middle class in Ukraine. Now the number of middle-income groups as the basis of the middle class, with its specific features in consumer and investment behavior, is being minimized. The income vector continues to shift to the plane of poverty, and it is doubtful whether the Ukrainian middle class will be able to transform into a powerful social group with its own characteristics in the near future.

The limited opportunities for the formation of the middle class by monetary factor in Ukraine is an extremely difficult problem, because traditionally the middle class performs such important functions in society as ensuring inclusive economic development, investing in services, paying taxes, which are further redistributed in favor of those who need social protection or support. At the same time, the noneconomic function of the middle class is leveled: participation in public and political institutions, ensuring control over the actions of the government, guaranteeing democratic freedoms, the formation of civil society, and so on. As a result, there is a partial adoption of the middle class functions by other population groups, which are mostly incapable to socially implement the ideological foundations of economic steadiness, social security and political stability. This situation significantly reduces the chances of dynamic social development in Ukraine. It is also alarming and worrying that, even with a balanced policy on changes in the field of distribution in Ukraine, it will take many decades to change the situation for the better [7].

An empirical study conducted by the authors using the tools of the sociological survey confirmed the theoretically substantiated conclusions about the significant differences in the indicators of the middle class, calculated by the monetary and sociological approach. The reason for this is the lack of sufficient opportunities needed to use knowledge, skills and professional competence in the form of a profitable economic asset in Ukraine. Representatives of traditional middle-class professions (teachers, physicians, professional psychologists, engineering and economic workers) of different age groups took part in the survey. The study involved all regions of Ukraine, and the share of respondents with a scientific degree and academic title, i.e. those whose professional competencies are formed as a result of significant social investment, amounted to $74.6 \%$ [8]. In terms of the research problem, this approach justified the representativeness of the sample, and the statistical error was not more than $2.3 \%$.

Thus, according to empirical research, it was found that the vast majority of respondents considered themselves to belong to the middle class cohort $(71.4 \%)$, even greater was the share of respondents in the group of people with a scientific degree and academic title $(83.7 \%)$. At the same time, the questions about the total income as a monetary criterion for the differentiation of the middle class received half as many positive answers. Only $36.7 \%$ of respondents said 
that they considered their income level to be in line with their idea of middle-class income. This situation proves the fact that the vast majority of middle-class professions in Ukraine consider themselves to belong to the appropriate stratum of society not on monetary but on sociological grounds [9]. In other words, there is an indirect identification of the middle class with the intelligentsia with its inherent functions and way of life. Among other things, this conclusion is based on respondents' answers to the question of whether their lifestyle, including the nature of costs and investment behavior, can be characterized as typical of the middle class? Despite the fact that only $28.6 \%$ of respondents rated their income as worthy of middle-class income, $41.7 \%$ believe that their lifestyle still corresponds to the lifestyle of the studied social group. There is a desperate desire of traditional middle class professions to belong to the relevant social class, though they understand the futility of such expectations in the near future, primarily because of minimizing the conditions necessary for the application of knowledge, skills and competences in the form of human capital.

Discussion of results. A paradoxical situation is observed in Ukraine. From a sociological point of view, the representatives of middle class are not the middle class according to the methodology of the monetary approach, and therefore they are unable to perform their stabilizing function in the socio-economic development of the state, and vice versa, a group of people with the income close to or even slightly higher than the median level, does not represent the traditional professions of the middle class, and therefore is unlikely to act as a guarantor of progressive socio-economic transformations in the short and long term. Unfortunately, Ukraine has chosen the labor model of socio-economic development, where the middleincome group is largely represented not by the intelligentsia, but by workers who have chosen an alternative of labor migration. The income of the latter is a prerequisite for the development of financial and commercial sphere and partly in the service sector. However, given that the real incomes received in these areas of employment are mostly in the shadows, the budgets of all levels of the state suffer and, as a result, its social security, economic steadiness and political stability are threatened.

At the same time, there is a blurring of the middle class professions and the decline of intellectual work. In this case, scholars and practitioners of public policy have no choice but to state the probability of multilayered middle class. However, the authors are deeply convinced that this is an extremely wrong position, because such a "multilayered" middle class is not and cannot be a carrier of common views and beliefs. On the contrary, it is in a state of exacerbation of internal contradictions, which negatively affects the general prospects of state formation. It is important to state the existence of the middle class by both criteria at the same time: monetary and sociological. Otherwise, the situation will indicate the internal economic and social segregation of the middle class, the deformation of its functions and role in society, the threat to economic steadiness and political stability in the state [10].

According to the authors, the middle class is not an abstract, multilayered, artificially united group of people, but a real social formation, a stratum characterized by specific interests, aspirations and norms of behavior, worldview and beliefs about priority areas and acceptable methods of reorganizing social relations. In this context, the conclusions of those scholars who claim the dynamic formation of the middle class in the vast majority of post-Soviet countries, including Ukraine, seem quite contradictory. As the results of the empirical study have shown, if we agree that the middle class exists in the third world countries, it is obvious that it is insignificant. In addition, it can be considered «middle» only conditionally, on the basis of total income, including various «merchants» and in no way teachers, scientists, physicians, engineers, technologists, military men, i.e. those who at all times were and remain the carriers of progressive judgments, ideas, motives and democratic values. The ideological basis of such a «middle class» can only be the pursuit of monetary gain, while those who by vocation could make, and in developed countries they do make the core of the middle class. In developing countries these categories of population do not make the middle class primarily because of scant income. At the same time, they usually have no influence on the course of transformational economic processes. The social strata, which are supposed to represent the values and the way of life of the middle class, are in a rather difficult situation, which hinders their implementation of functions similar to the functions of the middle class of developed countries.

\section{CONCLUSIONS}

Based on the results of theoretical generalizations and analysis of empirically obtained data, it is possible to formulate important conclusions for the science and practice of state formation. Thus, the creation of conditions for the knowledge application in the form of human capital is the main prerequisite for strengthening the middle class as a stratum of the population that determines the trends of state development in the field of economic stediness, social security and political stability. It is the powerful middle class that contributes to the development of the post-industrial, information economy and the establishment of a modern model of social development. On this basis, the authors claimed a crucial conclusion: the problems of the middle class and its impact on the system of social relations in the XXI century is directly related to the concept of human 
capital, the ability to use professional knowledge, statebuilding ideas, progressive beliefs and ideologies in the form of economic assets that brings profit and precedes the implementation of progressive distribution and redistribution principles in the system of socioeconomic relations.

As a result of the study, it is also stated that the middle class in Ukraine is not at the stage of its formation, but on the contrary, it undergoes destruction and segmental decline. The main problem is that the majority of those who perceive themselves as members of the middle class do not belong to it from a monetary point of view, and those who can be classified as middle class in terms of income are not, in fact, the carriers of progressive judgments about the state development. This leads to extremely negative consequences for the social cohesion of society as a factor of its development. The problems of social justice and motivation of the middle class to solve urgent issues in achieving the priorities of Ukraine as a modern state, worthy of integration into the European Union, are intensified.

\section{REFERENCES}

[1] Shultz, T. (1971), Investment in Human Capital, N.Y.; L.

[2] Melnychuk, D.P. (2015), Liudskyi kapital: priorytety modernizatsii suspilstva u konteksti polipshennia yakosti zhyttia naselennia [Human capital: priorities for modernization of society in the context of improving the quality of life], available at: http://www.idss.org.ua/monografii/2015_Melnic huk.pdf.

[3] Samuelson, P. (1992), Ekonomika [Economics], NPO «ALHON», VNYYSY, Moscow, Russia, 333 p.

[4] Daniel, B. (1973), The Coming of Post-industrial Society: A Venture in Social Forecasting, New York: Basic Books.

[5] Balitska, V.V. Blyzniuk, V.V. Krykun, O.I. Musina, L.A. Skrypnychenko, M.I. and other (2009), Stanovlennia serednoho klasu: dominanta natsionalnoi stratehii Ukrainy [Formation of the middle class: the dominant of the national strategy of Ukraine], Chetverta khvylia, Kyiv, Ukraine, $640 \mathrm{p}$.

[6] Cherenko, L.M. (2020), "Ukrainian middle class in the new millennium: trends and prospects", Demography and Social Economy, №4 (42), pp. 71-92.

DOI: https://doi.org/10.15407/dse2020.04.071.
[7] Li Bingshui, Hu Hong-wei and Yan Ya (2012), "The Impact of Human Capital on incomeBased on the Perspective of Education", International Journal of Education and Management Engineering, №12, pp. 16-20. DOI: 10.5815/ijeme.2012.12.03.

[8] Lytvynenko, V. Kryvoruchko, O. Lurie, I. Savina, N. Naumov, O. and Voronenko, M. (2020), "Comparative Studies of Self-organizing Algorithms for Forecasting Economic Parameters", International Journal of Modern Education and Computer Science, № 6, pp. 1-15. DOI: $10.5815 / \mathrm{ijmecs} .2020 .06 .01$

[9] Pooja, Yadav and Sangeeta, Dhall (2020), "Comparative Analysis of Steganography Technique for Information Security", International Journal of Mathematical Sciences and Computing, № 4, pp. 42-69. DOI: 10.5815/ijmsc.2020.04.05

[10] Samuel Ndichu, Sylvester McOyowo, Henry Okoyo and Cyrus Wekesa (2020), "A Remote Access Security Model based on Vulnerability Management", International Journal of Information Technology and Computer Science, № 5, pp. 38-51. DOI: 10.5815/ijitcs.2020.05.03. 